\title{
The COP9 signalosome counteracts the accumulation of cullin SCF ubiquitin E3 RING ligases during fungal development
}

\author{
Marcia Regina von Zeska Kress, ${ }^{1+\ddagger}$ \\ Rebekka Harting, ${ }^{1 \neq}$ Özgür Bayram, ${ }^{1}$ \\ Martin Christmann, ${ }^{1}$ Henriette Irmer, ${ }^{1}$ \\ Oliver Valerius, ${ }^{1}$ Josua Schinke, ${ }^{1}$ \\ Gustavo H. Goldman ${ }^{2,3}$ and Gerhard H. Braus ${ }^{1 *}$ \\ ${ }^{1}$ Institut für Mikrobiologie und Genetik, Georg-August- \\ Universität Göttingen, Grisebachstrasse 8, D-37077 \\ Göttingen, Germany. \\ ${ }^{2}$ Laboratório Nacional de Ciência e Tecnologia do \\ Bioetanol CTBE, Caixa Postal 6170, 13083-970 \\ Campinas, São Paulo, Brazil. \\ ${ }^{3}$ Faculdade de Ciências Farmacêuticas de Ribeirão \\ Preto, Universidade de São Paulo, São Paulo, Brazil.
}

\section{Summary}

Defects in the COP9 signalosome (CSN) impair multicellular development, including embryonic plant or animal death or a block in sexual development of the fungus Aspergillus nidulans. CSN deneddylates cullin-RING ligases (CRLs), which are activated by covalent linkage to ubiquitin-like NEDD8. Deneddylation allows CRL disassembly for subsequent reassembly. An attractive hypothesis is a consecutive order of CRLs for development, which demands repeated cycles of neddylation and deneddylation for reassembling CRLs. Interruption of these cycles could explain developmental blocks caused by csn mutations. This predicts an accumulation of neddylated CRLs exhibiting developmental functions when CSN is dysfunctional. We tested this hypothesis in A. nidulans, which tolerates reduced levels of neddylation for growth. We show that only genes for CRL subunits or neddylation are essential, whereas CSN is primarily required for development. We used functional tagged NEDD8, recruiting all three fungal cullins. Cullins are associated with the CSN1/CsnA subunit when deneddylation

Accepted 28 January, 2012. *For correspondence. E-mail gbraus@ gwdg.de; Tel. (+49) 551 393771; Fax (+49) 551 393330. 'Present address: Faculdade de Ciências Farmacêuticas de Ribeirão Preto, Universidade de São Paulo, Av. do Café S/N, CEP 14040-903, Ribeirão Preto, São Paulo, Brazil. 瓶oth authors contributed equally to this work. is defective. Two CRLs were identified which are specifically involved in differentiation and accumulate during the developmental block. This suggests that an active $\mathrm{CSN}$ complex is required to counteract the accumulation of specific CRLs during development.

\section{Introduction}

The proteome of a multicellular organism is highly dynamic due to controlled cycles of synthesis and degradation of proteins. The timely removal of critical proteins is crucial for various cellular processes, including transcriptional regulation and silencing, DNA repair, the cell cycle or differentiation. Protein life span control is required for complex processes as long-term memory, circadian rhythm, appropriate stress response, antigen presentation in the immune system or in combating diseases like cancer or viral infections (Hershko and Ciechanover, 1998; Spataro et al., 1998; Ciechanover et al., 2000).

One essential pathway of targeted protein degradation includes ubiquitination and the $26 \mathrm{~S}$ proteasome (Tyers and Jorgensen, 2000). Ubiquitin ( $\mathrm{Ub}$ ) is a conserved 76 amino acids protein that is attached covalently to lysine residues of substrate proteins. Ubiquitination can either reduce stability or change activity or localization of a protein. $\mathrm{Ub}$-conjugation requires the sequential action of the E1 Ub-activating enzyme, the E2 Ub-conjugating enzymes and the E3 Ub-ligases as specificity factors for substrates (Hershko and Ciechanover, 1998). The largest known class of ubiquitin ligases comprises the cullin-RING ligases (CRL) (Petroski and Deshaies, 2005). There are three major categories of cullins in fungi (CUL1, CUL3, CUL4), five categories in metazoa (CUL1 through CUL5), and additional CUL7 (Kipreos et al., 1996; Mathias et al., 1996; Dias et al., 2002) and PARC (Parkin-like cytoplasmic protein) (Skaar et al., 2007) in the human genome.

Each cullin forms a distinct class of CRL complexes with substrate recognition subunits, which can be combined with distinct adaptors. CUL1 (in yeast: Cdc53) functions as a stalk-like scaffold, anchoring simultaneously at one site the SKP1/F-box protein heterodimer, and at the other site the RBX1 RING finger protein. SKP1 connects the cullin to the F-box protein. F-box proteins represent 
the substrate receptors in the SKP1-CUL1-F-box (SCF) complex. The F-box protein bound substrate is positioned in the proximity of $\mathrm{Rbx} 1$ that recruits an $\mathrm{E} 2 \mathrm{Ub}$-conjugating enzyme. Approximately 70 different proteins with F-box domains were identified in Aspergillus nidulans (Busch et al., 2007; Draht et al., 2007), including one F-box protein, GrrA (Fbx29), which is specifically necessary for sexual development (Krappmann et al., 2006). The bound substrate, SCF and the E2 ubiquitin ligase engage in concerted interactions that commit catalysis yielding a covalent linkage of a first ubiquitin. This ubiquitin can be the substrate for further ubiquitination. A poly-ubiquitin chain at $\mathrm{K} 48$, one of seven lysine residues of ubiquitin, attached to the protein substrate, is the signature for proteasomemediated proteolysis (Ohta et al., 1999; Tan et al., 1999; Chen et al., 2000; Wu et al., 2000). CUL3 CRL complexes contain RBX1, but differ from other CRL classes in direct binding of the substrate recognition subunit to the $\mathrm{N}$-terminus of CUL3 using a BTB/POZ domain (Furukawa et al., 2003). CUL4 CRL complexes contain RBX1 and the adaptor protein DDB1. DDB1 binds to substrate recognition subunits that contain WD-repeats, which mediate interaction with DDB1 (Higa et al., 2006).

Despite the cullins diversity, each of the classes of CRL complexes is subjected to similar regulatory mechanisms including the ubiquitin-like protein NEDD8/Rub1. NEDD8 was originally discovered being neuronal-precursorcell expressed developmentally downregulated in mice (Kumar et al., 1992). It encodes a small protein of 81 amino acids, which is $60 \%$ identical and $80 \%$ homologous to ubiquitin (Kumar et al., 1993). The NEDD8 homologue in Saccharomyces cerevisiae is Rub1 (related to ubiquitin 1), composed of 77 amino acids and with $59 \%$ identity to the human protein (Liakopoulos et al., 1998).

The activity of CRL complexes is controlled by the covalent linkage of NEDD8 to a lysine of cullins. This process is called neddylation (rubylation in yeast) and has its own unique set of enzymes to ensure a conjugation pathway distinct from ubiquitin. It requires the Ula1/Uba3 E1 NEDD8-activating and the Ubc12 E2 NEDD8-conjugating enzyme. E3 NEDD8/Rub1p ligase activity has been attributed to the RING finger protein Rbx1 as well as Dcn1 (defective in cullin neddylation-1) in yeast (Morimoto et al., 2003; Kurz et al., 2005). Den1 interacts with NEDD8/Rub1 and cullins and increases the kinetics of the neddylation process (Kurz et al., 2005). It is also able to bind to the E2 NEDD8/Rub1-enzyme Ubc12 (Kurz et al., 2008). Similar to other ubiquitin-like proteins, NEDD8 is synthesized as a precursor with a C-terminal tail of different length depending on the species (Kerscher et al., 2006). Proteases process this tail, resulting in mature NEDD8 which exposes a di-glycine motif covalently linked to the substrate. Deletions of the yeast genes rub1, ubc12, ula1 or uba3, encoding components of the neddylation machinery, are viable (Hochstrasser, 1998; Lammer et al., 1998; Liakopoulos et al., 1998). However, the defects of the NEDD8 pathway in Schizosaccharomyces pombe, Caenorhabditis elegans, Drosophila melanogaster and mice, all show a lethal phenotype, demonstrating an essential role for NEDD8 in cell viability (Osaka et al., 2000).

The major $C R L$ deneddylase is the constitutive photomorphogenesis complex 9 (COP9), termed COP9 signalosome (CSN), which directly interacts with E3 Ub-ligases (Schwechheimer et al., 2001; Suzuki et al., 2002). CSN5/JAB1/CsnE is the only subunit conserved in all eukaryotes. It carries an MPN+ domain containing the JAMM motif conferring metalloprotease (deneddylation) activity (Cope et al., 2002). The MPN+ domain of CSN controls the activity of CRLs by cleaving the ubiquitin-like protein NEDD8/Rub1 from cullin (Lyapina et al., 2001; Yang et al., 2002). Neddylated E3 Ub-ligases are the key mediators of post-translational labelling of proteins for the proteasome (Petroski and Deshaies, 2005). In the filamentous fungus Aspergillus nidulans defects in the CSN lead to a block in sexual fruit body formation (Busch et al., 2003; 2007). Deletion of the gene for the subunit CSN5/ CsnE leads to strong changes in the transcriptome, the proteome and the metabolome (Nahlik et al., 2010). CSN is linked to several additional developmental functions, including light control of development, the protection against oxidative stress, acting as an internal trigger signal during development, and the control of secondary metabolites which function as pheromones or as protectors against fungivors (Nahlik et al., 2010). The relationship between CSN and the fungal-specific velvet complex, which also controls secondary metabolism and development, is yet unknown (Busch et al., 2003; 2007; Braus et al., 2010; Sarikaya Bayram et al., 2010; Bayram and Braus, 2012). A second regulator of proteasomal degradation is the cullin-associated NEDD8-dissociated protein 1 (Cand1). It binds to unneddylated cullins and prevents the formation of SCF complexes (Hwang et al., 2003). A. nidulans Cand1/CandA is split into two proteins where one polypeptide binds to the SKP1/SkpA adaptor site and recruits the second Cand1/CandA polypeptide interacting with the neddylation site. Both proteins are also necessary for accurate fungal development and secondary metabolism (Helmstaedt et al., 2011).

We addressed here the specific role of deneddylation for development, using the fungus $A$. nidulans as a simple model for a multicellular eukaryote. The neddylation machinery as well as most SCF complex subunits is essential for fungal viability. We found that defects in the CSN deneddylase result in the accumulation of distinct F-box proteins being associated to neddylated cullins as parts of SCF E3 ubiquitin ligase complexes. Two of these F-box proteins are required for precise development, suggesting 
that an intact CSN is required to allow accurate fungal differentiation.

\section{Results}

The constitutively expressed neddylation and ubiquitination machinery is essential for Aspergillus nidulans viability

The proteins for neddylation and ubiquitination, including $\mathrm{NEDD} 8 / \mathrm{NeddH}$, are highly conserved between human and the filamentous fungus $A$. nidulans. The $A$. nidulans (An) NEDD8 encoding gene neddH (AN6179.2) exhibits $75 \%$ identity to Homo sapiens (Hs). $\mathrm{NeddH} / \mathrm{Nedd} 8$ shares $55 \%$ identity with AnUbiquitin (AN2000.2), which has 96\% identity to HsUbiquitin (Galagan et al., 2005). The human proteins CUL1, SKP1 and RBX1 correspond to AnCulA (AN1019.2) with 46\% identity, AnSkpA (AN2302.2) with $58 \%$ and AnRbxA (AN8844.2) with 91\% identity respectively (http://blast.ncbi.nlm.nih.gov/Blast.cgi). Only SkpA has been previously described as SconC and has been isolated as part of the regulation of sulphur metabolism in A. nidulans (Piotrowska et al., 2000).

Aspergillus nidulans can grow vegetatively as a filament and has two developmental options (Fig. 1A). Asexual development is favoured in light and results in spores, which are released into the air. In the absence of light, sexual development is supported, resulting in complex, closed fruit bodies (cleistothecia) with sexual spores (Bayram et al., 2010; Bayram and Braus, 2012). Comparison of mRNA levels by quantitative RT-PCR (qRT-PCR) for neddH or ubcL (E2 NeddH-conjugating enzyme) representing the neddylation machinery, $\operatorname{csn} A$ or $\operatorname{csnE}$ as parts of the CSN deneddylase, and the transcriptional expression of $c u l A, r b x A$ and $s k p A$, as parts of the SCF complex, showed that all genes are constitutively expressed during all stages of the fungal life cycle (Fig. S1) with small variations. None of the genes showed a characteristic developmental expression pattern as the control, esdC. This gene is specifically induced during sexual development (Vienken and Fischer, 2006). Defects in the gene for Rub1/Nedd8 and the E2 Rub1-conjugating enzyme, ubc12, are not essential in budding yeast (Hochstrasser, 1998; Lammer et al., 1998; Liakopoulos et al., 1998). We analysed the role of neddH and $u b c L$, the rub1/nedd 8 and $u b c 12$ homologues of $A$. nidulans, for the fungal life cycle. Thus, we replaced the neddH and the $u b c L$ genes by a pyrithiamine (ptrA) selection marker in order to obtain deletion mutants for the corresponding genes. Heterokaryons could be obtained, containing two different types of nuclei with one intact copy of the gene and one deleted copy of the same gene (for details see Experimental procedures) (Osmani et al., 2006). However, the homokaryon, containing only nuclei with the deletion of neddH or $u b c L$, could not survive. This suggests that these components of the neddylation pathway are essential for $A$. nidulans (Fig. S2). In mammals, internal NEDD8 lysines were proposed as possible poly-neddylation sites (Ohki et al., 2009). However, several partial neddH deletions based on the position of the NEDD8 lysines (K11, K22 and K48) did also not result in viable homokaryons, suggesting that the entire neddH sequence is necessary for fungal viability (data not shown). A deletion analysis of genes encoding subunits of the SCF complex culA, rbxA and skpA revealed that also these genes are essential in $A$. nidulans (Fig. S2).

In summary, these data suggest that, in contrast to CSN mediated deneddylation (Busch et al., 2003; 2007), the neddylation pathway and the SCF complex are essential for fungal viability.

\section{Deletion of the gene for DcnA/Dcn1-neddylase decreases the cellular levels of neddylated proteins but still allows normal fungal development}

We analysed whether a subtle reduction of the neddylation machinery, which is essential for fungal growth, has an impact on fungal development. Dcn1 is an auxiliary Rub1/Nedd8 E3 ligase in Saccharomyces cerevisiae and higher eukaryotes. It interacts with NEDD8 itself, the RING finger protein Rbx1 and the NEDD8 E2 ligase Ubc12 (Morimoto et al., 2003; Kurz et al., 2005; 2008). Dcn1 increases the kinetics of the neddylation reaction (Kurz et al., 2005) by synergistic E3 ligase activity with the RING protein Rbx1 (Scott et al., 2010). The homologue protein in $A$. nidulans DcnA shows $23 \%$ amino acid identity to the yeast protein but contains the same domain of unknown function (DUF 298) as it is described for Dcn1 in S. cerevisiae (Yang et al., 2007; Kurz et al., 2008). We verified that DcnA of $A$. nidulans is the Dcn1 homologue by studying its interactions in vivo by bimolecular fluorescence complementation (BiFC) ( $\mathrm{Hu}$ et al., 2002). The $d c n A$ cDNA was fused to the $\mathrm{N}$-terminal part of eYFP, whereas neddH/nedd8, $r b x A / r b x 1$ (RING) and $u b c L /$ ubc12 (E2 ligase) cDNAs were fused to the C-terminal part. Only interacting proteins result in an eYFP fluorescent signal. Under promoter inducing growth conditions (nitrate) we observed a fluorescence signal in the cytoplasm as well as a strong signal in the nucleus of the cell (Fig. 1B). We found specific interactions between DcnA/ Dcn1 and RbxA/Rbx1 as well as with $\mathrm{NeddH} / \mathrm{Nedd} 8$ and the NEDD8 E2 ligase UbcL/Ubc12. This corroborates that DcnA/Dcn1 function is similarly connected to the neddylation process as in other organisms.

We deleted the gene for DcnA/Dcn1 to reduce the fungal neddylation machinery. The $d c n A$ deletion strain is viable and therefore not essential for $A$. nidulans growth (mature cleistothecia shown in Fig. 1A). We compared the neddylation pattern in mycelia of wild-type and the $d c n A$ 


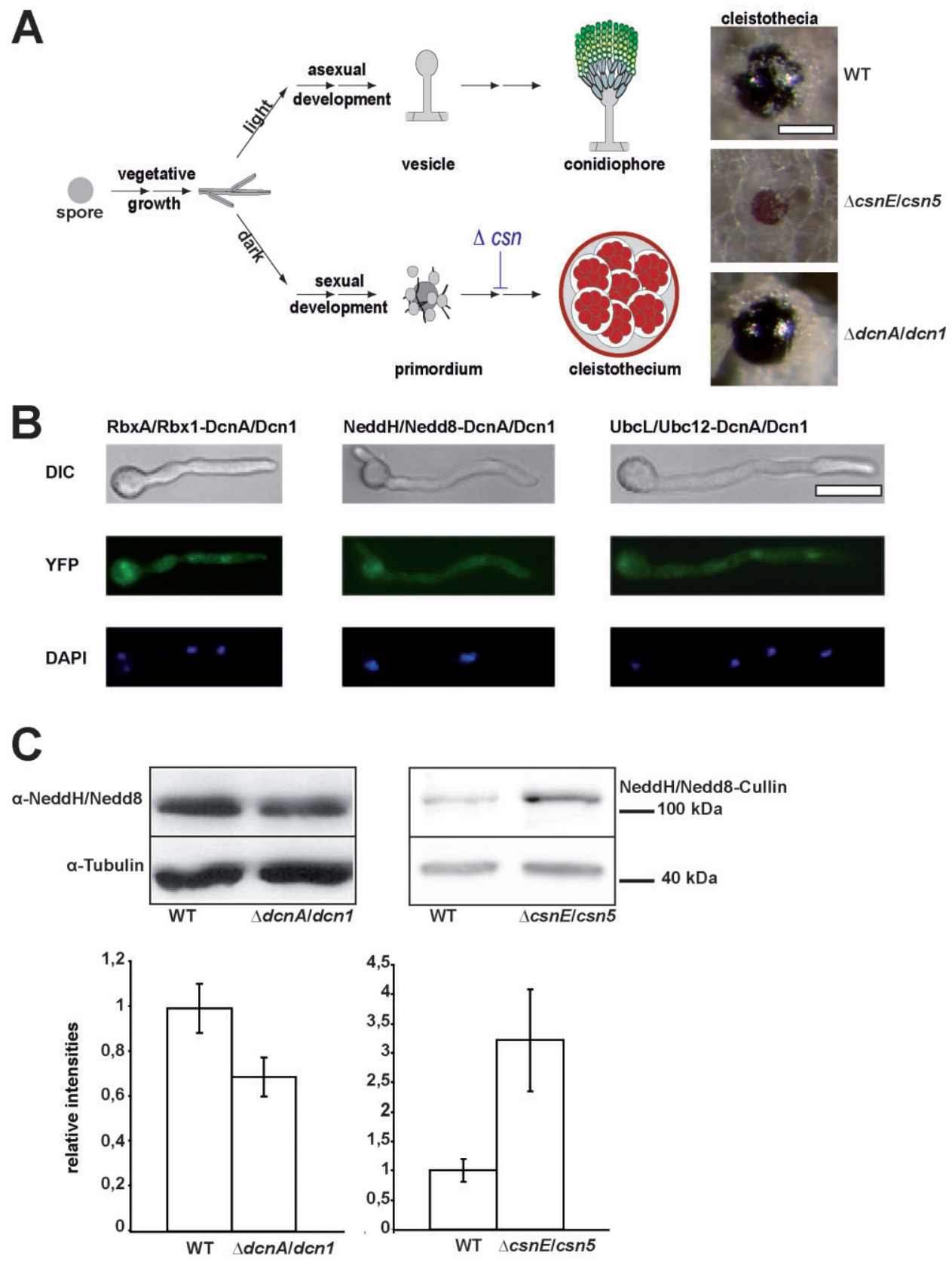

Fig. 1. Fungal development can cope with decreased neddylation in a $d c n A / d c n 1$ deletion strain.

A. Life cycle of $A$. nidulans wild-type and mutant strains. A spore germinates and develops to a vegetative mycelium. Depending on the environmental conditions, e.g. illumination, $A$. nidulans can form asexual structures, the conidiophores, in the light or sexual fruit bodies, the cleistothecia, in darkness (left). Whereas the WT and the $d c n A / d c n 1$ deletion strain form mature cleistothecia, the sexual fruit body development of the $c s n E / c s n 5$ deletion strain stops at the step of primordia (right; bar $100 \mu \mathrm{m}$ ). A total of $1 \times 10^{6}$ spores were plated on minimal medium and grown for 7 days at $37^{\circ} \mathrm{C}$ under sexual development inducing conditions.

B. Interaction partners of DcnA/Dcn1 visualized by bimolecular fluorescence complementation (BiFC). Indicated fungal strains were grown over night in $500 \mu \mathrm{l}$ London medium with nitrate for induction of the corresponding promoters. DIC, YFP and DAPI counterstained pictures of the respective hyphae are shown. YFP signals correspond to interactions of the N-terminal eYFP fused to DcnA/Dcn1 (N-eYFP::DcnA) with RbxA/Rbx1-, NeddH/Nedd8- and UbcL/Ubc12 fused to C-terminal eYFP [C-eYFP::NeddH (AGB 501), C-eYFP::RbxA (AGB 502), C-eYFP::UbcL (AGB 503)]. Negative control (AGB 500) showed no YFP signal (data not shown). Bar, $10 \mu \mathrm{m}$.

C. Neddylated proteins in various $A$. nidulans strains. Immunoblot analyses using $50 \mu \mathrm{g}$ protein extract of deletion strains with their corresponding parental strains with $\mathrm{NeddH} / \mathrm{Nedd} 8$ and tubulin antibody (left: WT and $\Delta d c n A / d c n 1$ (AGB 504); right: WT and $\Delta c s n E / c s n 5$ (AGB209). Strains were grown $20 \mathrm{~h}$ in liquid culture. Top: Shown is the most intensive signal with a size of around $108 \mathrm{kDa}$, representing neddylated cullin. Bottom: Quantification of signal intensities using Fusion-SL7 system with Bio1D software (Peqlab). The relative intensity of the deletion strains cullin band was put in relation to the WT, which relative intensity of the cullin band corresponds to 1 . The signal of tubulin was used as internal standard to normalize signal intensities. Data are derived from two (for AGB209) or three (for AGB504) independent experiments with four replications each.

(C) 2012 Blackwell Publishing Ltd, Molecular Microbiology, 83, 1162-1177 
deletion strain grown under vegetative conditions for $20 \mathrm{~h}$ using an antibody against NeddH/Nedd8. Western hybridizations revealed a corresponding prominent band in a size range of neddylated cullins. $\mathrm{NeddH} / \mathrm{Nedd} 8$ has a size of $9 \mathrm{kDa}$ in addition to the size of the three cullins CulA/Cul1 (89 kDa), CulC/Cul3 (94 kDa) and CulD/Cul4 $(100 \mathrm{kDa})$. The $d c n A / d c n 1$ deletion strain reduces the signal intensity of neddylated cullins in comparison to wild-type by approximately $30 \%$ using $\alpha$-tubulin as control (Fig. 1C). Analysis of the different phases of the fungal life cycle revealed that the reduction of neddylated cullins, as it is provided by the $d c n A$ deletion strain, does not result in a visible developmental defect during sexual (Fig. 1A) or asexual differentiation (data not shown). This suggests that the capacity of the fungal neddylation machinery is sufficiently high to tolerate subtle reductions without an impact on fungal development.

\section{Defects in the COP9 deneddylase result in accumulation of SCF complexes and a developmental block}

The $d c n A / d c n 1$ deletion strain reduces neddylated cullins in fungal cells without a developmental phenotype, whereas defects in the CSN deneddylase CsnE/Csn5 result in a block in sexual development (Busch et al., 2003; 2007). This corresponds to an approximately threefold increase of neddylated proteins in the csnE/csn5 deletion strain during vegetative growth in comparison to wild-type (Fig. 1C). We analysed which neddylated complexes have to be deneddylated during development. Therefore, we identified the proteins accumulating in a csnE/csn5 mutant when the fungus establishes developmental competence. This is the time point after a period of approximately $20 \mathrm{~h}$ of growth after germination. $A$. nidulans spores need this time to respond to external signals on a surface (Axelrod et al., 1973). For this purpose, we replaced the essential neddH gene for a neddH fusion to tap (tandem affinity purification) tag ( ${ }^{*}$ neddH) (Busch et al., 2007; Helmstaedt et al., 2008; Bayram et al., 2008b). The fusion corresponds to N-terminal TAP-tagged neddH derived from the cDNA fragment for the mature protein to avoid interference of the tag with the protease mediated maturation. Correct transformants were verified by Southern hybridization. The ${ }^{*}$ neddH was also introduced into the CSN-deficient $\Delta c s n E$ strain by crossing. Asexual and sexual development of tagged * nedd $H$ strains and the respective neddH wild-type strains were similar (Fig. 2A). Expression of the *neddH fusion gene was visualized by Western analysis using anti-calmodulin binding protein and anti-NeddH/Nedd8 antisera (Fig. 2B). This demonstrates that the $\mathrm{N}$-terminal TAP-tag at $\mathrm{NeddH} / \mathrm{Nedd} 8$ is neither interfering to cell viability and development nor to neddylation or deneddylation processes of $A$. nidulans.
The functional ${ }^{*} \mathrm{NeddH} / \mathrm{Nedd} 8$ was used to enrich $\mathrm{NeddH} / \mathrm{Nedd} 8$-containing complexes from fungal protein crude extracts. The fungus was cultivated for $30 \mathrm{~h}$ vegetatively until developmental competence has been acquired. Afterwards, it was further incubated for additional $48 \mathrm{~h}$ on solid medium under conditions directing towards sexual fruit body formation (darkness). Under these conditions there were no phenotypical differences between wildtype and csnE/csn5 mutant strains (Nahlik et al., 2010). Samples were subjected to gradient (8-20\%) SDS-PAGE analysis and the proteins were visualized using Colloidal blue staining (Fig. 2B). Primary bands were excised and identified by mass spectrometry (Fig. 2C). Among the identified proteins we detected all three cullins (CulA, CulC and CuID), which are present in the fungal genome (Galagan et al., 2005) in wild-type as well as in the csnE/csn5 deletion strain. ${ }^{*} \mathrm{NeddH} / \mathrm{Nedd} 8$ was found at the same molecular weight as all three cullins during vegetative growth and sexual development, suggesting the conjugation to * NeddH/Nedd8 in wild-type. The E1 NeddH/Nedd8activating enzymes UlaA and UbaC could be identified in wild-type as well as in the csnE/csn5 mutant. In contrast, the E2 NEDD8-conjugating enzyme UbcL was exclusively found in wild-type. This supports that in the absence of an active CSN deneddylase, when neddylated proteins are accumulated, the neddylation machinery is only partially recruited to neddylated cullins.

Furthermore, a protein with unknown function (AN4491) and the 60 S ribosomal protein L11 (AN4475) were identified in wild-type and mutant strain. Ribosomal Protein L11 was previously identified as target for the NEDD8 pathway (Xirodimas et al., 2008). A possible transcription factor $\mathrm{Zn}(\mathrm{II})(2) \mathrm{Cys}(6)$-domain containing protein (AN9050) was found exclusively in wild-type. Two other proteins with unknown function (AN4149 and AN8462) were only found in the csnE/csn5 mutant. These five proteins were not further investigated, because $\mathrm{NeddH} / \mathrm{Nedd} 8$ could not be co-identified with these proteins and their molecular weights also suggest that they are non-neddylated proteins, which might interact with the neddylation machinery or CRLs.

\section{The F-box proteins of accumulated SCF complexes in the CSN mutant are required for fungal development}

Several striking differences turned out between the TAP-tagged NeddH/Nedd8 ( ${ }^{*} \mathrm{NeddH} / \mathrm{Nedd} 8$ ) enriched proteins, which we identified from the deneddylase-deficient csnE/csn5 mutant strain and the wild-type $A$. nidulans (Fig. 2C). Only in the absence of csnE/csn5 we identified CsnA/Csn1, which has an essential role in CSN complex assembly (Wang et al., 2002). This might reflect a specific role of CsnA/Csn1 in the interaction of the CSN to neddylated Cullins. 


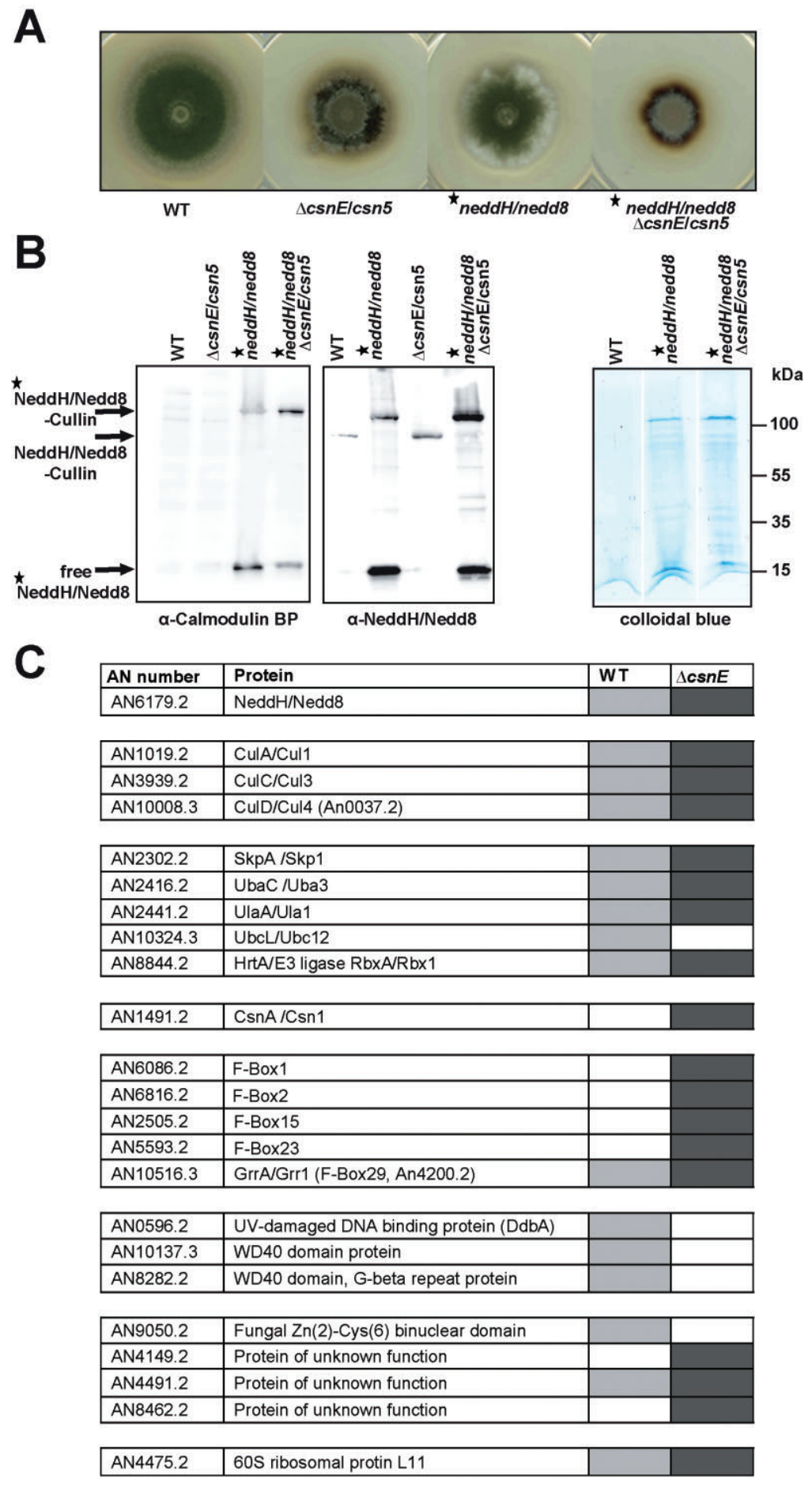

Fig. 2. Neddylated proteins in wild-type and csnE/csn5 A. nidulans mutant strains.

A. Growth of $A$. nidulans wild-type (TNO2a3) and the mutant strains $\Delta c s n E / c s n 5$ (AGB209), ${ }^{*}$ neddH/nedd8 (AGB457) and *neddH/nedd8 $\Delta c s n E / \operatorname{csn} 5$ (AGB460). A total of $1 \times 10^{6}$ spores were point inoculated on minimal medium and grown for $3-4$ days at $37^{\circ} \mathrm{C}$. B. Left: Neddylated proteins detected by $\mathrm{NeddH} / \mathrm{Nedd} 8$ immunoblot analysis of the wild-type (TNO2a3), $\Delta c s n E / c s n 5$ (AGB209), ${ }^{*}$ neddH/nedd8 (AGB457) and *neddH/nedd8 $\triangle c s n E / c s n 5$ (AGB460) with calmodulin binding protein and neddH/nedd8 antibodies. Strains were grown $20 \mathrm{~h}$ in liquid culture. Free $\mathrm{NeddH} / \mathrm{Nedd} 8$ without TAP tag cannot be visualized on the blot because of its small size. Right: Colloidal blue staining of an SDS Gel loaded with tandem affinity purified crude extracts of a WT (TNO2a3), * neddH/nedd8 (AGB457) and *neddH/nedd8 $\Delta c s n E / c s n 5$ (AGB460) strain.

C. Neddylated and $\mathrm{NeddH} / \mathrm{Nedd} 8$ associated proteins identified by Nano-LC-EST-MS2 after tandem affinity purifications with ${ }^{*} \mathrm{NeddH} / \mathrm{Nedd} 8$ in wild-type (WT) and $\triangle c s n E / c s n 5$ background. Left column: Aspergillus nidulans (AN) number; middle column: protein name; right column: strain background. " neddH $=$ neddH TAP tagged. Grey squares indicate in which genetic background the corresponding protein was identified.

Cullin 4 is known to link to DDB1, ROC1/RBX1 and substrate-specific adaptors WD40 repeat containing proteins (Higa et al., 2006). In addition to CulD/Cul4 we identified the protein DdbA/Ddb1 and two different WD40 repeat containing proteins (AN10134 and AN8282) in wild-type but not in the csnE/csn5 mutant strain. The RING protein RbxA/Rbx1/Hrt1 we found in both strains.
The assembly of these proteins with CulD/Cul4 might therefore be coordinated or controlled by a functional CSN-deneddylase complex.

The A. nidulans genome comprises approximately 70 F-box protein encoding genes which are normally bridged by SkpA (Skp1-homologue) to cullin-1 (CulA) (Galagan et al., 2005; Draht et al., 2007). There were hardly any 
F-box proteins identified as substrate recognition units for degradation by the Ub-proteasome system in wild-type fungi, due to the intact CSN-deneddylase, destabilizing SCF E3-Ub ligase complexes. These data go along with the increase of ${ }^{*} \mathrm{NeddH} / \mathrm{Nedd} 8-\mathrm{Cullin}$ complexes in the CsnE/Csn5 defective strain (Fig. 2B). In this strain the transient and dynamic SCF E3-Ub ligase complexes are stabilized. SkpA, the protein that bridges the F-box proteins to CulA, was present in wild-type as well as in the csnE/csn5 mutant. Once the neddylation process is active, SkpA is recruited to the neddylated SCF complex. The only F-box protein, which was found in wild-type and the mutant was the GrrA protein. It was shown that it is involved in ascosporogenesis during sexual development (Krappmann et al., 2006). The $\Delta g r r A$ strain cannot undergo meiosis and therefore displays a sterile phenotype. Several F-box proteins were exclusively recruited by ${ }^{*} \mathrm{NeddH} / \mathrm{Nedd} 8$ in the $c s n E / c s n 5$ strain but not in wildtype. This includes F-Box1 (AN6086), F-box2 (AN6816), F-box15 (AN2505) and F-box23 (AN5593) (Fig. 2C).

We examined whether we find factors among these F-box proteins, which play a role in fungal development. Four of the identified $f b x$ genes were deleted (Fig. 3A). The deletion of $f b \times 1$ and $f b \times 2$ resulted in wild-type-like asexual and sexual development. In contrast, deletion of fbx15 resulted in a fungal strain drastically reduced in both asexual and sexual development. Deletion of $f b x 23$ resulted in a strain, which in contrast to wild-type, is not repressed in sexual fruit body formation by light. It performs the sexual life cycle under conditions when the asexual development normally is preferred. These data suggest that the CSN is required to prevent the accumulation of neddylated SCF Ub-ligases. They include novel SCFs relevant for development, like SCF-Fbx15, or required for developmental control in response to environmental signals (light), as SCF-Fbx23. This SCF accumulation is linked to the observed block in sexual fruit body formation phenotype of a $c s n E / c s n 5$ mutant strain.

\section{CSN stabilizes the F-box protein Fbx15}

Several developmentally relevant F-box proteins were enriched by the TAP-tagged ${ }^{*} \mathrm{Nedd} / \mathrm{NeddH}$ in the CSNdeficient $\operatorname{csn} E / c s n 5$ deletion strain. We examined whether a developmental phenotype is typical for F-box encoding genes but could not find a single developmental phenotype when a sample of $20 \mathrm{~F}$-box protein encoding genes was deleted (data not shown). This suggests that the applied biochemical approach specifically enriched developmental F-box proteins. Further analysis addressed whether CSN affects the stability of Fbx15, as the deletion of the corresponding gene causes the most severe developmental phenotype in A. nidulans. A gene for GFP-tagged Fbx15 under the control of the constitutively active gpdA promoter was ectopically expressed in the wild-type and csn5/csnE deletion strains respectively. Transformants were verified by Southern hybridization (data not shown). Two strains, which showed similar expressions of the Fbx15 encoding gene in quantitative real-time PCR, were cultivated. Proteins were extracted from vegetative cultures and GFPFbx15 levels were compared by western hybridization using anti-GFP and as control anti-actin antisera (Fig. 3C). The wild-type and csn5/csnE deletion strains show significant differences in the overall Fbx15 protein levels, suggesting that $\mathrm{CSN}$ is required to stabilize the $\mathrm{Fbx} 15$ protein pool. Protein synthesis was stopped by cycloheximide and the Fbx15 protein levels were monitored at different time points. These data further corroborated that the Fbx15GFP fusion protein was more stable in the wild-type strain than in the csn5/csnE deletion strain. This suggests that $\mathrm{CSN}$ is required for stabilizing the pool of Fbx15. Presumably, the subpopulation of the protein, which is arrested at the neddylated SCFs during development, was biochemically enriched in the $\operatorname{csn} \mathrm{E} / \operatorname{csn} 5$ mutant. The data suggest that without an active CSN deneddylase the neddylation/ deneddylation cycles are interrupted and the overall pool of Fbx15 is destabilized.

\section{Discussion}

Dynamic and transient cycles of neddylation and deneddylation have been proposed to regulate the activity of CRL E3 ubiquitin-ligases catalysing the final step in ubiquitination. This labelling controls stability, activity or localization of target proteins (Wee et al., 2002; Bayram et al., 2010; Helmstaedt et al., 2011). We used the fungus A. nidulans as multicellular model system, which does not only produce filaments but specialized tissue to form fungal fruit bodies. Neddylation and deneddylation are not equally important in fungal life, because only neddylation is required for fungal growth as a modular filament. Deneddylation is only required when the fungus is forming the more differentiated cell types (Busch et al., 2003; 2007). We analysed the developmental block caused by defects in deneddylation biochemically and could identify developmentally relevant fungal CRLs.

The highly conserved eukaryotic NEDD8 is expressed in most tissues of plants, slime moulds, fungi and animals (Kumar et al., 1993; Rao-Naik et al., 1998; Burroughs et al., 2007; Ande et al., 2009). Similar to A. nidulans, proteins involved in the neddylation process are required for cell viability in S. pombe (Osaka et al., 2000). Studies in other organisms revealed that defects in this process also cause drastic flaws in survival due to development instability in D. melanogaster (Ou et al., 2002), or early defects in embryogenesis in C. elegans and mice (Jones and Candido, 2000; Tateishi et al., 2001). All enzymes responsible for neddylation might act in a complex in 
A
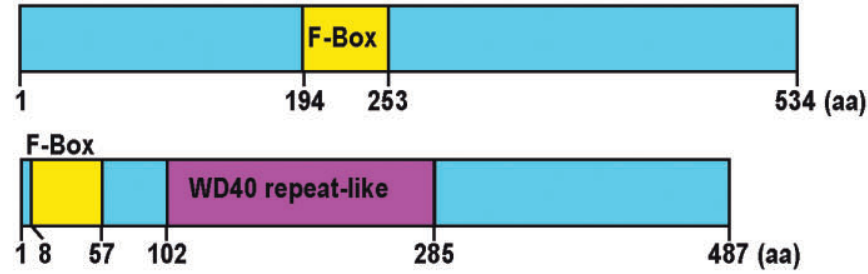

Fbox1 (AN6086)
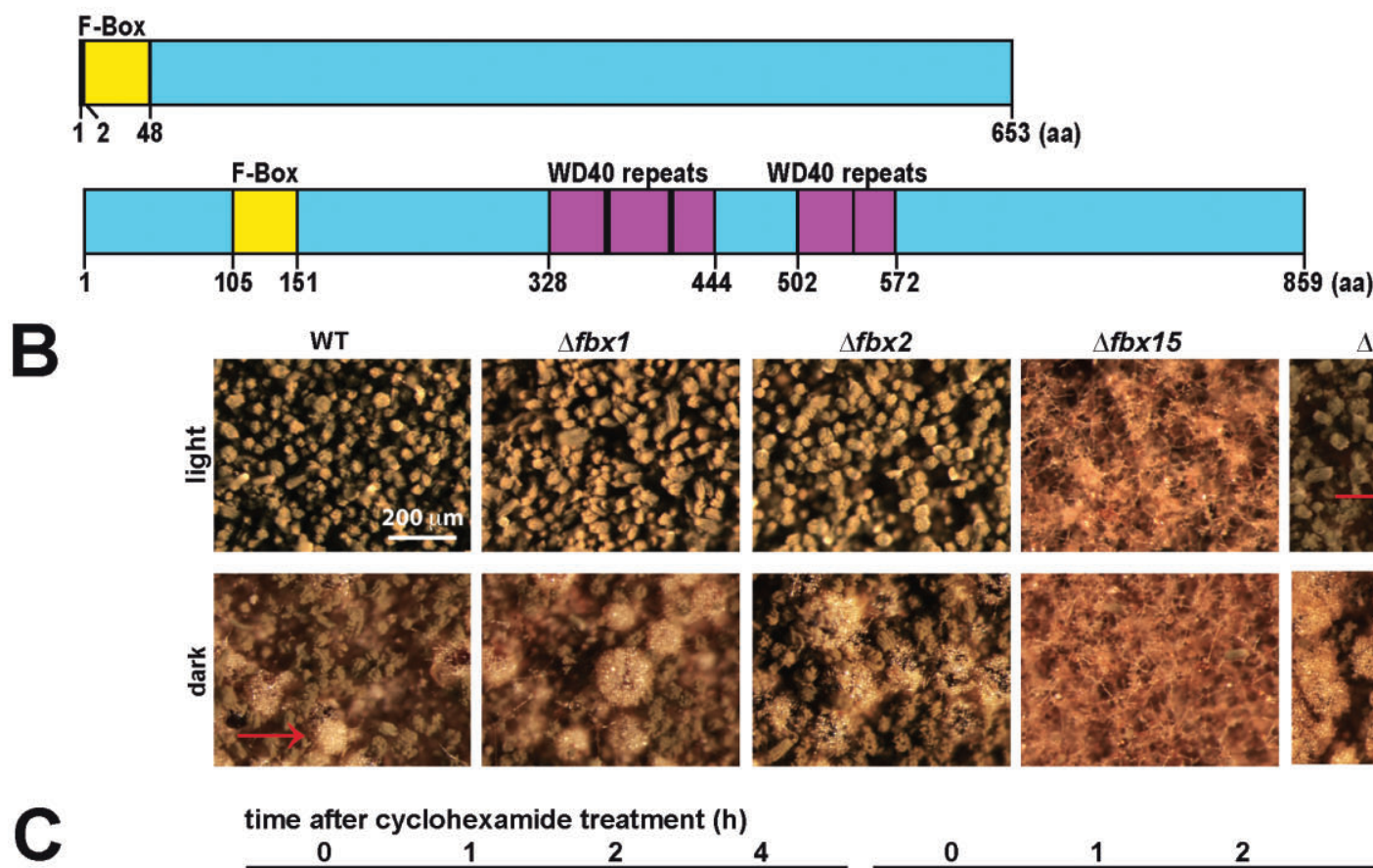

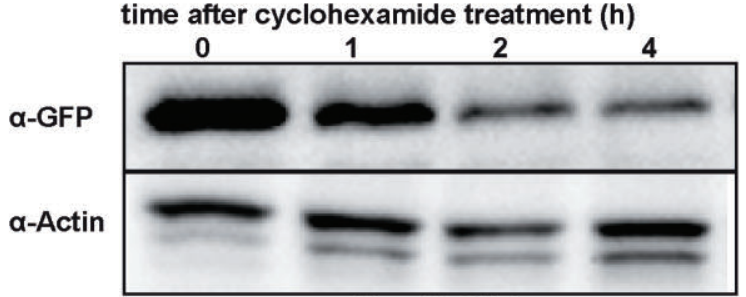

Fbox15-GFP
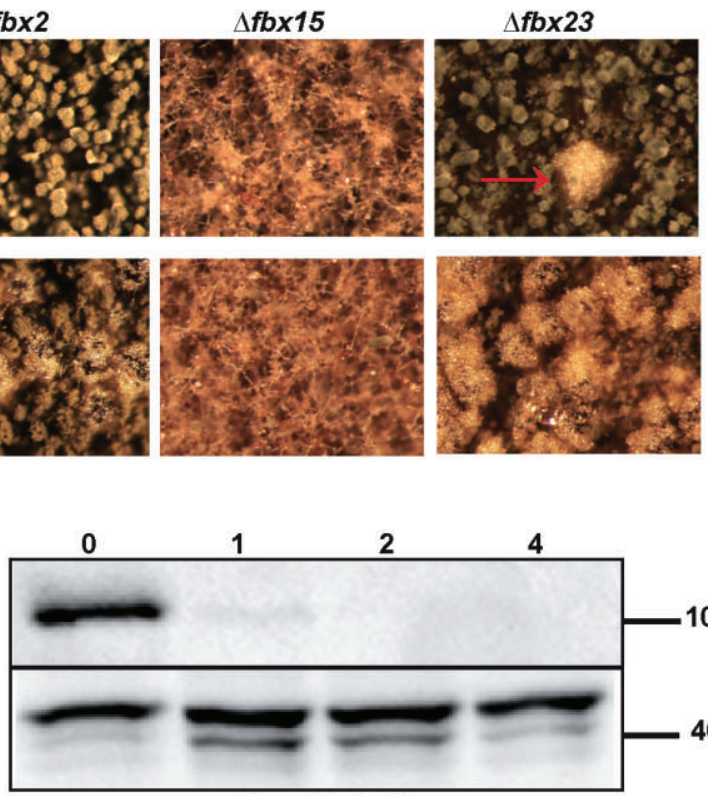

1 2 4

Fbox23 (AN5593)

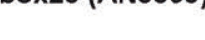

Fbox15 (AN2505) 
antagonistic process to neddylation (Schwechheimer and Deng, 2001; Suzuki et al., 2002). CSN is required for the control of hormone signalling and tumour growth by regulation of c-Jun and p53 protein levels in mammalian cells (Li et al., 2000; Pollmann et al., 2001). In insects and plants, CSN malfunction results in post-embryonic lethality (Wei et al., 1994; Freilich et al., 1999). It remains yet unclear how deregulation of CSN leads to tumour formation, but a variety of studies concerning human cancers show the overexpression of especially subunit CSN5 in these tissues (Kato and Yoneda-Kato, 2009). Various fungal CSN complexes known to date are involved in cellular processes, like circadian clock regulation, cell cycle progression, and pheromone response (Mundt et al., 1999; Maytal-Kivity et al., 2003; He et al., 2005).

The $A$. nidulans CSN deneddylase controls fungal development by the correct balance of fungal hormones (Nahlik et al., 2010). CSN complex formation as well as a functional JAMM-deneddylase motif has been shown to be critical in fungal development (Busch et al., 2003; 2007). We found here several consequences on a molecular level which are caused by defects in the CSN deneddylase. (i) CsnA/Csn1, which is the second largest protein of the CSN complex, is recruited to neddylated cullins. CsnA/Csn1 has been found in a CSN subcomplex together with the CSN subunits 2, 3 and 8 . A second subcomplex includes CsnE/ Csn5 and both subcomplexes have been proposed to be linked by CSN1 and CSN6 (Fu et al., 2001; Sharon et al., 2006; 2009; Dessau et al., 2008). Thus, the absence of a functional CSN-deneddylation subcomplex (CSN4,5,6,7) might stabilize the Csn1/CsnA interaction to neddylated CRL-complexes. (ii) The deneddylase activity seems to be further important for the assembly of CulD/Cul4 to DdbA/ Ddb1, RbxA/Hrt1/Rbx1 and WD40 proteins, which are not found in the absence of a functional deneddylase. (iii) In contrast, CulA/Cul1 can interact with SCF compounds in the absence of the CSN-deneddylase process. (iv) Neither in the presence nor in the absence of an intact CSN interactors of CulC/Cul3 were identified under the tested conditions. Currently, we do not know, whether this might reflect that the formation of $\mathrm{CulC} / \mathrm{Cul} 3$ complexes is more transient.

(v) The major finding is that TAP tagged $\mathrm{NeddH} / \mathrm{Nedd} 8$ recruited several developmental relevant $\mathrm{F}$-box proteins in the csnE/csn5 deletion strain. Our data show that overexpression of $f b \times 15$ leads to high and stable levels of this protein in a wild-type fungus, where CSN is intact and cycles of neddylation and deneddylation are possible. In contrast, a deneddylase-deficient csnE/csn5 deletion strain destabilizes Fbx15. This is consistent with human cell lines, where the protein levels of F-box proteins are decreased upon down regulation of CSN5 caused by autoubiquitination (Cope and Deshaies, 2006). A possible explanation might be that the absence of a functional CSN complex arrests a small subpopulation of specific F-box proteins in SCF complexes. This can be enriched biochemically, whereas the free pool of this F-box protein is instable. The corresponding interaction in wild-type might be more transient and more dynamic and might result in an overall protection of the F-box protein. This suggests that the wild-type fungus with an intact deneddylation machinery stabilizes Fbx15 which might be due to neddylation and deneddylation cycles preventing autoubiquitination. CSN controls the disassembly of F-box proteins from SCF complexes, whereas the SkpA/Skp1 binding to CulA/Cul1 seems to be independent of the CSN-deneddylase activity. Fungal development requires one major permanently assembled SCF, which is GrrA/Fbx29 corresponding to Grr1 in yeast. GrrA in A. nidulans is required for the production of mature sexual ascospores (Krappmann et al., 2006) and the SCF-GrrA can be as well found in the presence or absence of the CSN. The process of sexual reproduction in $A$. nidulans is linked to amino acid starvation (Eckert et al., 1999) and a specific expression of the putative hexose transporter HxtA was observed (Wei et al., 2004). Defects in Grr1 can also result in developmental defects in yeast (Butler et al., 2006), which is presumably a consequence of the physiological role of Grr1. SCF-Grr1 complexes in yeast are important regulators for adapting to different nutrient conditions. In the presence of glucose, Grr1 mediates the degradation of Mth1, which is a negative regulator for the expression of hexose transporter encoding genes (Flick et al., 2003; Spielewoy et al., 2004). Furthermore, SCF-Grr1-mediated protein degradation has a role in the activation of genes encoding amino acid permeases (Iraqui et al., 1999; Bernard and Andre, 2001).

From approximately 70 possible SCF complexes only a small subpopulation accumulates during fungal development when the COP9 deneddylase is not functional. This links the accumulation of these SCF complexes on a molecular level to the different phenotypes of the csnE/ csn5 mutant strain. This mutant is not only blocked in sexual development but also insensitive against the environmental signal 'light' with defects in hormone sensing and secondary metabolism (Busch et al., 2007; Nahlik et al., 2010). SCF complexes with different F-box proteins might have different target proteins for ubiquitination. The role of the F-box proteins Fbx1 and Fbx2, which associate in the absence of the CSN-deneddylase is not yet elucidated. Fbx15 and Fbx23 seem to have distinct and at least partially antagonistic functions during development. Fbx15 is required for asexual as well as for sexual development. Fbx23 is required for the developmental decision during illumination when asexual development is promoted and simultaneously sexual development is reduced. Similar to GrrA/Fbx29, Fbx23 seems to be required for ascospore maturation and to develop fully grown sexual fruit bodies. In contrast, $\Delta f b x 15$ shows almost no cleistothecia. In 
A. nidulans, one important regulator of secondary metabolism and development is the velvet complex composed of VelB/VeA/LaeA. Deletions in the genes encoding VeA and VelB result in a loss of cleistothecia formation (Bayram et al., 2008b), whereas the deletion of the gene encoding the methyltransferase LaeA leads to constitutive sexual development and a reduction in fruit body size (Sarikaya Bayram et al., 2010). The molecular connection between the described F-box proteins and the regulators of the velvet complex is still elusive.

Our data suggest that development of a complicated multicellular structure, as a fungal fruit body, requires an accurate sequence of SCF activities. Defects in the deneddylase required for SCF E3-Ub ligase complex disassembly disturbs development presumably by the accumulation of specific SCF activities. It will be interesting to see whether an accumulation of developmentally relevant SCF complexes can be also observed during embryonic development of plants or mammals with impaired deneddylase activity.

\section{Experimental procedures}

\section{Strains, media and growth conditions}

The A. nidulans strains used in this study are listed in Table S1. The media used were minimal media (MM; $1 \%$ glucose, original high-nitrate salts, trace elements, $2 \%$ agar, $\mathrm{pH}$ 6.5) with or without $1.2 \mathrm{M}$ sorbitol (SORB) and supplemented with $0.1 \%$ pyridoxine- $\mathrm{HCl}$ (PYRO), $5 \mathrm{mM}$ each uridine and uracil (UU). Trace elements, vitamins and nitrate salts were included as described by Käfer (1977). BiFC media nitrate promoter control: London medium consists of $1 \%$ glucose, $2 \%$ salt solution $\left[26 \mathrm{~g} \mathrm{l}^{-1} \mathrm{KCl}, 26 \mathrm{~g} \mathrm{l}^{-1} \mathrm{MgSO}_{4}\right.$, $76 \mathrm{~g} \mathrm{l}^{-1} \mathrm{KH}_{2} \mathrm{PO}_{4}, 5 \%(\mathrm{v} / \mathrm{v})$ trace elements] pH 6.5 plus $10 \mathrm{mM}$ $\mathrm{NaNO}_{3}$ or $5 \mathrm{mM} \mathrm{NH}_{4}$-tartrate. Standard genetic techniques for A. nidulans were used for all strain construction (Käfer, 1977). Escherichia coli strain $\mathrm{DH} 5 \alpha$ was employed for the preparation of plasmid DNA and grown in Luria-Bertani (LB) medium ( $1 \%$ tryptophan, $0.5 \%$ yeast extract, $1 \% \mathrm{NaCl})$ in the presence of $100 \mathrm{\mu g} \mathrm{ml}^{-1}$ ampicillin.

\section{Transformation procedures}

Escherichia coli cells were transformed as described previously (Inoue et al., 1990). A. nidulans was transformed by polyethylene glycol-mediated fusion of protoplasts as described previously (Punt \& van den Hondel, 1992).

PCR-mediated construction of neddH, culA, skpA, rbxA, dcnA and ubcL deletion cassettes and Heterokaryon Rescue Technique

The neddH, culA, skpA and $u b c L$ knockout cassettes were generated by applying the ptrA resistance marker from $A$. oryzae (Kubodera et al., 2000), and rbxA knockout cassette was generated by applying the pyrG auxotrophic marker from A. fumigatus. From each gene a 2000 bp 5'- and 3'-flanking fragment was amplified via PCR using $A$. nidulans TNO2a3 (Nayak et al., 2006) gDNA as a template. Fusion PCR was applied according to Szewczyk et al. (2006). Briefly, the PCR primers were synthesized with '20 bp tails' such that the gene flanking region fragments anneal to the marker during fusion PCR. Fusion PCR has created a cassette containing the marker surrounded by the genes flanking sequences and transformation with this fragment has led to replacement of the gene with the marker. The polymerase used to amplify the fragments as well the fusion PCR was Platinum ${ }^{\circledR}$ Taq DNA polymerase High Fidelity (Invitrogen) or Phusion High Fidelity polymerase (Finnzymes). The sequence of the primers used in this assay is listed in Table S3 and the deletion cassettes were constructed with the following primers: neddH - MK003, MK025, MK026, MK027, MK028 and MK007; culA - MK042, MK043, MK044, MK045, MK046 and MK047; rbxA - RH043, $\mathrm{RH} 044, \mathrm{RH} 045, \mathrm{RH} 046, \mathrm{RH} 047$ and $\mathrm{RH} 048 ; s k p A-\mathrm{MK} 206$, MK207, MK208, MK209, MK210 and MK211; dcnA - RH011, $\mathrm{RH} 012, \mathrm{RH} 013, \mathrm{RH} 014, \mathrm{RH} 015$ and RH016; and $u b c L$ MK089, MK090, MK091, MK092, MK093 and MK094. The fusion PCR-mediated cassettes were transformed into the strain TNO2a3. In case of at least three transformations that were not successful, the corresponding deletion strain was tested with the Heterokaryon Rescue Technique according to Osmani et al. (2006). The fusion PCR-generated deletion cassettes were transformed in the TNO2a3 strain and recovered by selection with $100 \mathrm{ng} \mathrm{ml}^{-1}$ pyrithiamine ( $p$ trA selective marker) or $1.2 \mathrm{~g} \mathrm{l}^{-1}$ uridine and uracil (UU-Afu pyrG auxotrophic marker) in the culture media. Spores of primary transformants were replica streaked onto new agar plates with and without the addition of the selection (pyrithiamine or UU) and incubated for $48 \mathrm{~h}$ at $30^{\circ} \mathrm{C}$. During asexual spore formation, heterokarya carrying both marker $(-)$ geneX $(+)$ parental nuclei and deleted marker $(+)$ geneX $(-)$ nuclei produced uninucleate spores with either type of nuclei. When these mixed spores were inoculated on non-selective media, the marker $(-)$ geneX $(+)$ spores have germinated and have grown into colonies. The marker $(+)$ geneX $(-)$ spores have germinated but arrested growth due to lack of geneX function. However, the same mixed spores from the heterokaryon streaked on selective media are unable to form colonies because the marker $(-)$ geneX $(+)$ spores cannot grow in the presence of pyrithiamine (100 $\left.\mathrm{ng} \mathrm{ml}^{-1}\right)$ and the marker (+) geneX (-) spores cannot form colonies without geneX function. Homologous integration of each cassette at the locus of the gene of interest was monitored by PCR using primers with homology for the region direct after or before the gene in the $5^{\prime}$ or $3^{\prime}$-flanking region and other primers upstream or downstream of the $2000 \mathrm{bp} \mathrm{5'-} \mathrm{or} 3^{\prime}$-flanking region. The following primers were used and the sequences are listed in Table S3: neddH - MK026 and MK041, MK032 and MK041; culA MK138 and MK139; rbxA - RH066 and RH067, RH066 and RH046; skpA - MK212 and MK213; and ubcL - MK190 and MK193. The dcnA deletion strain (AGB504) was confirmed by Southern hybridization using the $3^{\prime}$-flanking region as probe (amplified with $\mathrm{RH} 015$ and $\mathrm{RH} 016$ ).

\section{Construction of Fbox deletion strains}

Deletion cassettes were generated using fusion PCR as described before (Szewczyk et al., 2006). The auxotrophic 
marker was amplified from plasmid pCDA21 (Chaveroche et al., 2000), and is referred to as zeo-pyrG cassette, because the amplified fragment contains the zeocin-resistance gene and the $A$. fumigatus pyrG gene. The marker was fused to the $5^{\prime}$ - and $3^{\prime}$-flanking regions of the F-box genes and the cassettes were transformed into TNO2A3 (Nayak et al., 2006). The following primers were used and the sequences are listed in Table S3: fbx1-01-1, 01-2, 01-3, 01-4, 01-zeo, 01-pyr, fbx202-1, 02-2, 02-3, 02-4, 02-zeo, 02-pyr, fbx15-15-1, 15-2, 15-3, 15-4, 15-zeo, 15-pyr, fbx23-23-1, 23-2, 23-3, 23-4, 23-zeo, 23-pyr.

\section{Plasmid and strain construction for bimolecular fluorescence complementation (BiFC) and fluorescence microscopy}

Plasmids used in this study are listed in Table S2. The cDNA of dcnA (primers $\mathrm{RH} 017$ and $\mathrm{RH} 018$ ) and $r b x A$ (primers MK097 and MK098) were amplified from an $A$. nidulans cDNA library derived from RNA of vegetative grown wild-type mycelia and ligated into the pJET 1.2/ blunt vector (Fermentas) resulting in the plasmids pME3671 and pME3672.

The cDNA of $d c n A$ was amplified from pME3672 (primers $\mathrm{RH} 097$ and $\mathrm{RH} 098$ ) and fused to the $\mathrm{N}$-Terminal part of eYFP amplified from pME3012 (primers RH099 and OLKM91) (Blumenstein et al., 2005) by fusion PCR (Szewczyk et al., 2006). The construct was cloned into plasmid pME3160 (Bayram et al., 2008b) containing a bidirectional niiA/niaD promoter using the Pmel site resulting in plasmid pME3673. cDNAs of rbxA (primers $\mathrm{RH} 101$ and MK030), neddH (primers MK98 and $\mathrm{RH} 100$ ) and $u b c L$ (primers MK96 and RH102) were amplified from the plasmids pME3671, pME3005 and pME3678 and fused to the C-terminal part of eYFP amplified from pME3013 (primers OLKM86 and OLKM87) by fusion PCR. Fusion constructs were ligated into pME3673 using the Swal restriction site resulting in the plasmids pME3674 (eyfp::rbxA), pME3675 (eyfp::neddH) and pME3676 (eyfp::ubcL). As control the $\mathrm{C}$-terminal part of eYFP alone was ligated into pME3673 using the Swal restriction site resulting in pME3677. The plasmids were transformed into the $A$. nidulans strain AGB152, resulting in the strains AGB500, AGB501, AGB502 or AGB503 respectively. Ectopical integration was confirmed by Southern hybridization with a nitrate promoter probe amplified from genomic DNA of the wild-type strain A4 (primers OLKM67 and OLKM68). The strains were incubated in London media supplemented with nitrate to induce the promoter, or with ammonium to repress the promoter. Microscopy was performed as described (Helmstaedt et al., 2008).

\section{Construction of a mature TAP-tagged neddH cDNA $\left({ }^{*} \mathrm{NeddH}\right)$ cassette and introduction into A. nidulans wild-type and $\Delta$ csnE strain}

The DNA-cassette containing the mature neddH cDNA sequence (without the $C$-terminal processed part) fused at its $5^{\prime}$ end with the TAP-tag ( $S$. aureus protein A, TEV, calmodulin binding domains) sequence was constructed using fusion PCR strategy (Szewczyk et al., 2006) and ligation reactions. The construction into the vector pGEM®- 5 Zf $(+) /$ nTAP (Busch et al., 2007) was performed in two steps. First, the ligation of the fusion PCR-mediated cassette neddH cDNA::neddHterminator (411 bp)::pyroA (A. fumigatus auxotrophic marker)::neddH $3^{\prime}$-flanking region (2000 bp) into the Sacl and Mlul restriction sites of the vector pGEM@- $5 Z f(+) / n T A P$. The PCRamplified nedd $\mathrm{H}^{\prime}$ '-flanking region (2000 bp) was ligated in the Sphl and Apal restriction sites of the previous vector, resulting in the plasmid pME3612. The template and primers used to amplify the fragments were: (i) pME3005 to amplify the mature neddH (MK029 and MK030); (ii) genomic DNA of TNO2a3 strain to amplify $2000 \mathrm{bp}$ neddH 5'-flanking region (MK003 and MK004), 411 bp terminator (MK031 and MK005R) and 2000 bp neddH 3'-flanking region (MK006F and MK007); and (iii) genomic DNA of Aspergillus fumigatus to amplify pyroA auxotrophic marker (MK005F and MK006R). The primer sequences used for amplification are listed in the Table S3. The PCR reaction, as well as the fusion PCR, was performed with Platinum $®$ Taq DNA polymerase High Fidelity (Invitrogen) or Phusion High Fidelity Polymerase (Finnzymes) respectively. The cassette was removed from the vector by digestion with $\mathrm{BamHI}$ and introduced by transformation in $A$. nidulans TNO2a3 strain and integrated into the neddH locus. The transformants were recovered onto selective culture medium $(\mathrm{MM}+\mathrm{UU}+\mathrm{SORB})$. The integration of TAP-tag::neddH ( ${ }^{*}$ neddH) cassette into the locus of neddH was confirmed by Southern hybridization and also, the DNA sequence region was verified by sequencing (data not shown). The TAPtag::neddH cDNA $\triangle c s n E A$. nidulans strain is the result of a genetic crossing of TAP-tag::neddHcDNA strain with the strain AGB209.

\section{Plasmid and strain construction for Fbx15-GFP overexpression}

The fbx15::gfp fusion was generated using fusion PCR (Szewczyk et al., 2006). fbx15 was amplified from genomic DNA of $A$. nidulans using the primers OZGFBX15-Start and OZGFBX15-GFP. sgfp was amplified from pME3185 (Bayram et al., 2008a) using the primers OZG207 and OZG208. The two fragments were fused in equimolar amounts with the primers OZG15-Start and OZG208. The fbx15-sgfp fusion was cloned into the Pmel restriction site of pME3856, resulting in plasmid pME3950. The plasmid was ectopically introduced into AGB152 and AGB209. The resulting strains AGB678 and AGB679 were verified by Southern hybridization and RNA expression levels were confirmed by qRT-PCR using the primers JS110 and JS111.

\section{Tandem affinity purification (TAP)-tag purification}

TAP was performed by the modified method of Busch et al. (2007). Briefly, the total protein of TAP-tag:: neddH cDNA strain and its parental strain (TNO2a3), as well as the TAPtag::neddH cDNA $\triangle$ csnE were extracted by incubation of the grinded mycelia or sexual structures in liquid nitrogen with mortar and pestle with BufferB ${ }^{*}[300 \mathrm{mM} \mathrm{NaCl}, 100 \mathrm{mM}$ Tris- $\mathrm{HCl} \mathrm{pH} 7.2,10 \%$ glycerol, $0.1 \% \mathrm{NP}-40,1 \mathrm{mM}$ dithiothreitol (DTT), and protease inhibitors cocktail - Complete, EDTA-free; Roche]. The purification was followed by incubation of the crude extract with IgG-agarose (Amersham 
Biosciences/GE Healthcare) for $3 \mathrm{~h}$ on a rotating platform at $4^{\circ} \mathrm{C}$. The suspension was poured into a Bio-Rad PolyPrep column (Bio-Rad Laboratories), in which beads were washed twice with IPP300 (25 mM Tris- $\mathrm{HCl}$ pH 8.0, $300 \mathrm{mM} \mathrm{NaCl}$, $0.1 \% \mathrm{NP}-40,2 \mathrm{mM} \mathrm{DTT}$ ), once with IPP150 (25 mM Tris-HCl $\mathrm{pH} 8.0,150 \mathrm{mM} \mathrm{NaCl}, 0.1 \% \mathrm{NP}-40,2 \mathrm{mM}$ DTT), and once with tobacco etch virus (TEV) cleavage buffer $(25 \mathrm{ml}$ Tris- $\mathrm{HCl}$ $\mathrm{pH} 8.0,150 \mathrm{mM} \mathrm{NaCl}, 0.1 \%$ NP-40, $0.5 \mathrm{mM}$ EDTA, $1 \mathrm{mM}$ DTT). In the sealed column, beads were incubated with $1 \mathrm{ml}$ of TEV cleavage buffer containing $300 \mathrm{U}$ TEV protease on a rotating platform for $16 \mathrm{~h}$ at $4^{\circ} \mathrm{C}$. Proteins cleaved from the beads were eluted into a reaction tube, and elution was repeated with $1 \mathrm{ml}$ of TEV cleavage buffer. After addition of $6 \mathrm{ml}$ calmodulin binding buffer (CBB; $25 \mathrm{mM}$ Tris- $\mathrm{HCl} \mathrm{pH}$ 8.0, $150 \mathrm{mM} \mathrm{NaCl}, 1 \mathrm{mM} \mathrm{Mg}$ acetate, $1 \mathrm{mM}$ imidazole, $2 \mathrm{mM}$ $\mathrm{CaCl}_{2}, 10 \mathrm{mM} \beta$-mercaptoethanol) and $6 \mu$ of $1 \mathrm{M} \mathrm{CaCl}_{2}$, the solution was incubated with calmodulin beads (Stratagene) on a rotating platform for $4 \mathrm{~h}$ at $4^{\circ} \mathrm{C}$. The calmodulin beads were equilibrated with $5 \mathrm{ml}$ of CBB prior to incubation and after incubation were washed twice with $1 \mathrm{ml}$ of CBB containing $0.1 \% \mathrm{NP}-40$ and with $1 \mathrm{ml}$ of CBB containing $0.02 \%$ NP-40. Proteins were eluted with $3 \mathrm{ml}$ of Calmodulin elution buffer (CEB - 25 mM Tris-HCl pH 8.0, 150 mM NaCl, 0.02\% NP-40, $1 \mathrm{mM} \mathrm{Mg}$ acetate, $1 \mathrm{mM}$ imidazole, $20 \mathrm{mM}$ EGTA, $10 \mathrm{mM} \beta$-mercaptoethanol). The final eluate was precipitated by trichloroacetic acid (TCA), including the adjustment of aliquots to $25 \% \mathrm{TCA}$, incubation $16 \mathrm{~h}$. Centrifugation at $4^{\circ} \mathrm{C}$, $10000 \mathrm{~g}$ for $1 \mathrm{~h}$, and two washes with cold acetone. After being dried in a speed vacuum, the pellet was resuspended in protein loading dye. After separation on a SDS-PAGE gradient gel electrophoresis (8-20\%) protein bands were stained with Colloidal blue staining and cut out of the gel.

\section{Protein identification by tandem mass spectrometry}

Peptides of in-gel trypsinated proteins (Shevchenko et al., 1996) were extracted from gel slices of stained protein bands and separated on a NAN75-15-03-C18-PM column with an ultimate 3000 HPLC system (Dionex, Amsterdam, the Netherlands) prior to mass analyses with a LCQ DecaXP mass spectrometer (Thermo Scientific, San Jose, USA). Cycles of MS spectra with $\mathrm{m} / \mathrm{z}$ ratios of peptides and four datadependent MS2 spectra were recorded by mass spectrometry. The 'peak list' was created with extractms provided by the Xcalibur software package (BioworksBrowser 3.3.1SP1). The MS2 spectra were analysed against the $A$. nidulans genome protein database (http://www.broad.mit.edu/ annotation/genome/aspergillus_nidulans/Home.html) using the Turbo-SEQUEST program (Lundgren et al., 2005) of Bioworks (Thermo Scientific). Protein identification required at least two different high scoring peptides meeting the following criteria: (i) XCorr $(1+, 2+, 3+)>2.0,2.5,3.0$; (ii) $\Delta C n>0.4$; and (iii) $\mathrm{Sp}>500$. MS2 spectra of the highest scoring peptides were individually verified.

\section{Vegetative, sexual and asexual development induction}

The conidia from $A$. nidulans strains were grown in a reciprocal shaker at $30^{\circ} \mathrm{C}$ for $16-24 \mathrm{~h}$ in liquid MM medium (plus supplementation if necessary). Mycelia were aseptically transferred to fresh $\mathrm{MM}$ agar medium and incubated at $30-37^{\circ} \mathrm{C}$ to induce the asexual (presence of light and normal aeration) and sexual (absence of light and sealed plates) development. Each sample was harvested by filtration through Miracloth sheet, washed thoroughly with washing solution $(0.98 \% \mathrm{NaCl}$, $1 \mathrm{mM}$ phenylmethylsulphonyl fluoride), 1\% dimethylsulphoxide) and quickly frozen in liquid nitrogen. The time-points collected were: vegetative $24 \mathrm{~h}$ (v24), asexual development 12, 24, $48 \mathrm{~h}$ (a12, a24, a48), and sexual development 24, 48, $72 \mathrm{~h}$ (s24, s48, s72).

\section{Protein stability assay using cycloheximide}

Strains were grown under vegetative conditions for $20 \mathrm{~h}$ in liquid minimal medium at $37^{\circ} \mathrm{C}$. The mycelium was harvested by filtration through a sterile miracloth sheet, washed with $0.98 \% \mathrm{NaCl}$ solution and further incubated in liquid MM containing $25 \mu \mathrm{g} \mathrm{ml}^{-1}$ cycloheximide for 1,2 and $4 \mathrm{~h}$ at $37^{\circ} \mathrm{C}$.

\section{Protein assays and Western hybridization analysis}

The total protein was extracted by grinding the mycelia and incubating it at $4^{\circ} \mathrm{C}$ with extraction buffer $(300 \mathrm{mM} \mathrm{NaCl}$, $100 \mathrm{mM}$ Tris- $\mathrm{HCl} \mathrm{pH} 7.2,10 \%$ glycerol, $0.1 \%$ NP-40, $1 \mathrm{mM}$ DTT, and protease inhibitors cocktail - Complete, EDTA-free; Roche). The protein concentration was determined by use of a modified Bradford assay (Bio-Rad), and samples bands were fractionated in SDS-PAGE gradient (8-20\%) or $12 \%$ non-gradient gel. After protein separation, the gel was blotted onto a pure nitrocellulose membrane $(0.2 \mu \mathrm{m}$; Bio-Rad), and after being blocked in $5 \%$ dried milk TBS/T buffer $(10 \mathrm{mM}$ Tris- $\mathrm{HCl} \mathrm{pH} \mathrm{8.0,} 150 \mathrm{mM} \mathrm{NaCl}, 0.05 \%$ Tween 20), the membrane was probed with anti-Calmodulin binding protein antibody (Upstate/Millipore), GFP antibody (Santa Cruz), actin antibody (Sigma), tubulin antibody (Sigma) or anti-NeddH/ Nedd8 antibody (Genescript) respectively. As secondary antibody horseradish peroxidase-coupled goat anti-rabbit IgG (Invitrogen) or rabbit anti-mouse (Jackson ImmunoResearch) was used. The blot was developed by enhanced chemiluminescence method (Tesfaigzi et al., 1994). The signals intensity was quantified using Fusion-SL7 system with Bio1D software (Peqlab). As control strains the corresponding parental strains $\mathrm{TNO}_{2} \mathrm{a} 3$ for the $d c n A$ deletion strain and AGB152 for the csnE deletion strain were used.

\section{mRNA isolation}

Aspergillus nidulans mycelia was disrupted by grinding with liquid nitrogen, and total RNA was extracted with RNeasy plant Kit (Qiagen). To verify RNA integrity, $20 \mu \mathrm{g}$ of RNA from each sample was fractionated in $2.2 \mathrm{M}$ formaldehyde, $1.2 \%$ agarose gel, stained with ethidium bromide, and visualized with UV light. The presence of intact $28 \mathrm{~S}$ and $18 \mathrm{~S}$ ribosomal RNA bands was used as the criteria to determine if the RNA was degraded.

\section{RT-PCR and quantitative PCR}

DNase digestion and subsequent cDNA synthesis was carried out in duplicates for each sample using $0.8 \mu \mathrm{g}$ of RNA with the QuantiTect Reverse Transcription Kit (Qiagen). Amplification was performed in a LightCycler 2.0 (Roche) 
with the RealMaster SYBR Rox Kit (5Prime) using $1 \mu \mathrm{l}$ of a $1 / 10$ dilution of the cDNA and $A$. nidulans primers (Table S3). Amplification conditions were as follows: 36 cycles of $15 \mathrm{~s}$ at $95^{\circ} \mathrm{C}, 22 \mathrm{~s}$ at $64^{\circ} \mathrm{C}, 22 \mathrm{~s}$ at $70^{\circ} \mathrm{C}$, and an adjacent melting step $\left(42-95^{\circ} \mathrm{C}\right)$. The amount of gene of interest relative to histone H2A RNA was quantified using the $\triangle \mathrm{CT}$ method with efficiency (Pfaffl et al., 2002). All qRT-PCR experiments were performed at least in triplicate.

\section{Acknowledgement}

We thank G. Heinrich for excellent technical assistance and E. Fedotova, J. Gerke and B. Joehnk for critically reading the manuscript. This research has been supported by grants from the Deutsche Forschungsgemeinschaft, SPP 1365, FOR 1334, SFB 860, the Volkswagen-Stiftung, the Fonds der Chemischen Industrie and the TRANSPAT project of EraNet PathoGenoMics. M. R. von Zeska Kress was supported by the Alexander-von-Humboldt-Stiftung.

\section{References}

Ande, S.R., Chen, J., and Maddika, S. (2009) The ubiquitin pathway: an emerging drug target in cancer therapy. Eur $J$ Pharmacol 625: 199-205.

Axelrod, D.E., Gealt, M., and Pastushok, M. (1973) Gene control of developmental competence in Aspergillus nidulans. Dev Biol 34: 9-15.

Bayram, O., and Braus, G.H. (2012) Coordination of secondary metabolism and development in fungi: the velvet family of regulatory proteins. FEMS Microbiol Rev 36: 1-24.

Bayram, O., Biesemann, C., Krappmann, S., Galland, P., and Braus, G.H. (2008a) More than a repair enzyme: Aspergillus nidulans photolyase-like CryA is a regulator of sexual development. Mol Biol Cell 19: 3254-3262.

Bayram, O., Krappmann, S., Ni, M., Bok, J.W., Helmstaedt, K., Valerius, O., et al. (2008b) VelB/VeA/LaeA complex coordinates light signal with fungal development and secondary metabolism. Science 320: 1504-1506.

Bayram, O., Braus, G.H., Fischer, R., and RodriguezRomero, J. (2010) Spotlight on Aspergillus nidulans photosensory systems. Fungal Genet Biol 47: 900-908.

Bernard, F., and Andre, B. (2001) Ubiquitin and the SCF(Grr1) ubiquitin ligase complex are involved in the signalling pathway activated by external amino acids in Saccharomyces cerevisiae. FEBS Lett 496: 81-85.

Blumenstein, A., Vienken, K., Tasler, R., Purschwitz, J., Veith, D., Frankenberg-Dinkel, N., and Fischer, R. (2005) The Aspergillus nidulans phytochrome FphA represses sexual development in red light. Curr Biol 15: 1833-1838.

Braus, G.H., Irniger, S., and Bayram, O. (2010) Fungal development and the COP9 signalosome. Curr Opin Microbiol 13: $672-676$

Burroughs, A.M., Balaji, S., lyer, L.M., and Aravind, L. (2007) Small but versatile: the extraordinary functional and structural diversity of the beta-grasp fold. Biol Direct 2: 18.

Busch, S., Eckert, S.E., Krappmann, S., and Braus, G.H. (2003) The COP9 signalosome is an essential regulator of development in the filamentous fungus Aspergillus nidulans. Mol Microbiol 49: 717-730.
Busch, S., Schwier, E.U., Nahlik, K., Bayram, O., Helmstaedt, K., Draht, O.W., et al. (2007) An eight-subunit COP9 signalosome with an intact JAMM motif is required for fungal fruit body formation. Proc Natl Acad Sci USA 104: 80898094.

Butler, D.K., All, O., Goffena, J., Loveless, T., Wilson, T., and Toenjes, K.A. (2006) The GRR1 gene of Candida albicans is involved in the negative control of pseudohyphal morphogenesis. Fungal Genet Biol 43: 573-582.

Chaveroche, M.K., Ghigo, J.M., and d'Enfert, C. (2000) A rapid method for efficient gene replacement in the filamentous fungus Aspergillus nidulans. Nucleic Acids Res 28: E97.

Chen, A., Wu, K., Fuchs, S.Y., Tan, P., Gomez, C., and Pan, Z.Q. (2000) The conserved RING-H2 finger of ROC1 is required for ubiquitin ligation. J Biol Chem 275: 1543215439.

Ciechanover, A., Orian, A., and Schwartz, A.L. (2000) Ubiquitin-mediated proteolysis: biological regulation via destruction. Bioessays 22: 442-451.

Cope, G.A., and Deshaies, R.J. (2006) Targeted silencing of Jab1/Csn5 in human cells downregulates SCF activity through reduction of F-box protein levels. BMC Biochem 7: 1.

Cope, G.A., Suh, G.S., Aravind, L., Schwarz, S.E., Zipursky, S.L., Koonin, E.V., and Deshaies, R.J. (2002) Role of predicted metalloprotease motif of Jab1/Csn5 in cleavage of Nedd8 from Cul1. Science 298: 608-611.

Dessau, M., Halimi, Y., Erez, T., Chomsky-Hecht, O., Chamovitz, D.A., and Hirsch, J.A. (2008) The Arabidopsis COP9 signalosome subunit 7 is a model $\mathrm{PCl}$ domain protein with subdomains involved in COP9 signalosome assembly. Plant Cell 20: 2815-2834.

Dias, D.C., Dolios, G., Wang, R., and Pan, Z.Q. (2002) CUL7: a DOC domain-containing cullin selectively binds Skp1. Fbx29 to form an SCF-like complex. Proc Natl Acad Sci USA 99: 16601-16606.

Draht, O.W., Busch, S., Hoffman, K., Braus-Stromeyer, S., Helmstaedt, K., Goldman, G.H., and Braus, G.H. (2007) Amino acid supply of Aspergillus. In The Aspergilli: Genomics, Medical Aspects, Biotechnology and Research Methods. Goldman, G.H., and Osmani, S.A. (eds). New York: CRC Press, pp. 143-175.

Eckert, S.E., Hoffmann, B., Wanke, C., and Braus, G.H. (1999) Sexual development of Aspergillus nidulans in tryptophan auxotrophic strains. Arch Microbiol 172: 157-166.

Flick, K.M., Spielewoy, N., Kalashnikova, T.I., Guaderrama, M., Zhu, Q., Chang, H.C., and Wittenberg, C. (2003) Grr1dependent inactivation of Mth1 mediates glucose-induced dissociation of Rgt1 from HXT gene promoters. Mol Biol Cell 14: 3230-3241.

Freilich, S., Oron, E., Kapp, Y., Nevo-Caspi, Y., Orgad, S., Segal, D., and Chamovitz, D.A. (1999) The COP9 signalosome is essential for development of Drosophila melanogaster. Curr Biol 9: 1187-1190.

Fu, H., Reis, N., Lee, Y., Glickman, M.H., and Vierstra, R.D. (2001) Subunit interaction maps for the regulatory particle of the $26 \mathrm{~S}$ proteasome and the COP9 signalosome. EMBO J 20: 7096-7107.

Furukawa, M., He, Y.J., Borchers, C., and Xiong, Y. (2003) Targeting of protein ubiquitination by BTB-Cullin 3-Roc1 ubiquitin ligases. Nat Cell Biol 5: 1001-1007. 
Galagan, J.E., Calvo, S.E., Cuomo, C., Ma, L.J., Wortman, J.R., Batzoglou, S., et al. (2005) Sequencing of Aspergillus nidulans and comparative analysis with $A$. fumigatus and A. oryzae. Nature 438: 1105-1115.

$\mathrm{He}, \mathrm{Q}$., Cheng, P., and Liu, Y. (2005) The COP9 signalosome regulates the Neurospora circadian clock by controlling the stability of the SCFFWD-1 complex. Genes Dev 19: 15181531.

Helmstaedt, K., Laubinger, K., Vosskuhl, K., Bayram, O., Busch, S., Hoppert, M., et al. (2008) The nuclear migration protein NUDF/LIS1 forms a complex with NUDC and BNFA at spindle pole bodies. Eukaryot Cell 7: 1041-1052.

Helmstaedt, K., Schwier, E.U., Christmann, M., Nahlik, K., Westermann, M., Harting, R., et al. (2011) Recruitment of the inhibitor Cand1 to the cullin substrate adaptor site mediates interaction to the neddylation site. Mol Biol Cell 22: $153-164$.

Hershko, A., and Ciechanover, A. (1998) The ubiquitin system. Annu Rev Biochem 67: 425-479.

Higa, L.A., Wu, M., Ye, T., Kobayashi, R., Sun, H., and Zhang, H. (2006) CUL4-DDB1 ubiquitin ligase interacts with multiple WD40-repeat proteins and regulates histone methylation. Nat Cell Biol 8: 1277-1283.

Hochstrasser, M. (1998) There's the rub: a novel ubiquitinlike modification linked to cell cycle regulation. Genes Dev 12: 901-907.

Hu, C.D., Chinenov, Y., and Kerppola, T.K. (2002) Visualization of interactions among bZIP and Rel family proteins in living cells using bimolecular fluorescence complementation. Mol Cell 9: 789-798.

Hwang, J.W., Min, K.W., Tamura, T.A., and Yoon, J.B. (2003) TIP120A associates with unneddylated cullin 1 and regulates its neddylation. FEBS Lett 541: 102-108.

Inoue, H., Nojima, H., and Okayama, H. (1990) High efficiency transformation of Escherichia coli with plasmids. Gene 96: 23-28.

Iraqui, I., Vissers, S., Bernard, F., de Craene, J.O., Boles, E., Urrestarazu, A., and Andre, B. (1999) Amino acid signaling in Saccharomyces cerevisiae: a permease-like sensor of external amino acids and F-Box protein Grr1p are required for transcriptional induction of the AGP1 gene, which encodes a broad-specificity amino acid permease. Mol Cell Biol 19: 989-1001.

Jones, D., and Candido, E. (2000) The NED-8 conjugating system in Caenorhabditis elegans is required for embryogenesis and terminal differentiation of the hypodermis. Dev Biol 226: 152-165.

Käfer, E. (1977) Meiotic and mitotic recombination in Aspergillus and its chromosomal aberrations. Adv Genet 19: 33-131.

Kato, J.Y., and Yoneda-Kato, N. (2009) Mammalian COP9 signalosome. Genes Cells 14: 1209-1225.

Kerscher, O., Felberbaum, R., and Hochstrasser, M. (2006) Modification of proteins by ubiquitin and ubiquitin-like proteins. Annu Rev Cell Dev Biol 22: 159-180.

Kipreos, E.T., Lander, L.E., Wing, J.P., He, W.W., and Hedgecock, E.M. (1996) cul-1 is required for cell cycle exit in C. elegans and identifies a novel gene family. Cell 85: 829-839.

Krappmann, S., Jung, N., Medic, B., Busch, S., Prade, R.A., and Braus, G.H. (2006) The Aspergillus nidulans F-box protein GrrA links SCF activity to meiosis. Mol Microbio/61: 76-88.

Kubodera, T., Yamashita, N., and Nishimura, A. (2000) Pyrithiamine resistance gene (ptrA) of Aspergillus oryzae: cloning, characterization and application as a dominant selectable marker for transformation. Biosci Biotechnol Biochem 64: 1416-1421.

Kumar, S., Tomooka, Y., and Noda, M. (1992) Identification of a set of genes with developmentally down-regulated expression in the mouse brain. Biochem Biophys Res Commun 185: 1155-1161.

Kumar, S., Yoshida, Y., and Noda, M. (1993) Cloning of a cDNA which encodes a novel ubiquitin-like protein. Biochem Biophys Res Commun 195: 393-399.

Kurz, T., Ozlu, N., Rudolf, F., O’Rourke, S.M., Luke, B., Hofmann, K., et al. (2005) The conserved protein DCN-1/ Dcn1p is required for cullin neddylation in C. elegans and S. cerevisiae. Nature 435: 1257-1261.

Kurz, T., Chou, Y.C., Willems, A.R., Meyer-Schaller, N., Hecht, M.L., Tyers, M., et al. (2008) Den1 functions as a scaffoldtype E3 ligase for cullin neddylation. Mol Cell 29: 23-35.

Lammer, D., Mathias, N., Laplaza, J.M., Jiang, W., Liu, Y., Callis, J., et al. (1998) Modification of yeast Cdc53p by the ubiquitin-related protein rub1p affects function of the SCFCdc4 complex. Genes Dev 12: 914-926.

Li, S., Liu, X., and Ascoli, M. (2000) p38JAB1 binds to the intracellular precursor of the lutropin/choriogonadotropin receptor and promotes its degradation. J Biol Chem 275: 13386-13393.

Liakopoulos, D., Doenges, G., Matuschewski, K., and Jentsch, S. (1998) A novel protein modification pathway related to the ubiquitin system. EMBO J 17: 2208-2214.

Lundgren, D.H., Han, D.K., and Eng, J.K. (2005) Protein identification using TurboSEQUEST. Curr Protoc Bioinformatics Chapter 13: Unit 13.3.

Lyapina, S., Cope, G., Shevchenko, A., Serino, G., Tsuge, T., Zhou, C., et al. (2001) Promotion of NEDD-CUL1 conjugate cleavage by COP9 signalosome. Science 292: 13821385.

Mathias, N., Johnson, S.L., Winey, M., Adams, A.E., Goetsch, L., Pringle, J.R., et al. (1996) Cdc53p acts in concert with Cdc4p and Cdc34p to control the G1-to-Sphase transition and identifies a conserved family of proteins. Mol Cell Biol 16: 6634-6643.

Maytal-Kivity, V., Pick, E., Piran, R., Hofmann, K., and Glickman, M.H. (2003) The COP9 signalosome-like complex in S. cerevisiae and links to other $\mathrm{PCl}$ complexes. Int $J$ Biochem Cell Biol 35: 706-715.

Morimoto, M., Nishida, T., Nagayama, Y., and Yasuda, H. (2003) Nedd8-modification of Cul1 is promoted by Roc1 as a Nedd8-E3 ligase and regulates its stability. Biochem Biophys Res Commun 301: 392-398.

Mundt, K.E., Porte, J., Murray, J.M., Brikos, C., Christensen, P.U., Caspari, T., et al. (1999) The COP9/signalosome complex is conserved in fission yeast and has a role in $\mathrm{S}$ phase. Curr Biol 9: 1427-1430.

Nahlik, K., Dumkow, M., Bayram, O., Helmstaedt, K., Busch, S., Valerius, O., et al. (2010) The COP9 signalosome mediates transcriptional and metabolic response to hormones, oxidative stress protection and cell wall rearrangement during fungal development. Mol Microbiol 78: 964-979. 
Nayak, T., Szewczyk, E., Oakley, C.E., Osmani, A., Ukil, L., Murray, S.L., et al. (2006) A versatile and efficient genetargeting system for Aspergillus nidulans. Genetics 172: 1557-1566.

Ohki, Y., Funatsu, N., Konishi, N., and Chiba, T. (2009) The mechanism of poly-NEDD8 chain formation in vitro. Biochem Biophys Res Commun 381: 443-447.

Ohta, T., Michel, J.J., Schottelius, A.J., and Xiong, Y. (1999) ROC1, a homolog of APC11, represents a family of cullin partners with an associated ubiquitin ligase activity. Mol Cell 3: 535-541.

Osaka, F., Saeki, M., Katayama, S., Aida, N., Toh, E.A., Kominami, K., et al. (2000) Covalent modifier NEDD8 is essential for SCF ubiquitin-ligase in fission yeast. EMBO $J$ 19: 3475-3484.

Osmani, A.H., Oakley, B.R., and Osmani, S.A. (2006) Identification and analysis of essential Aspergillus nidulans genes using the heterokaryon rescue technique. Nat Protoc 1: 2517-2526.

Ou, C.Y., Lin, Y.F., Chen, Y.J., and Chien, C.T. (2002) Distinct protein degradation mechanisms mediated by Cul1 and Cul3 controlling Ci stability in Drosophila eye development. Genes Dev 16: 2403-2414.

Petroski, M.D., and Deshaies, R.J. (2005) Function and regulation of cullin-RING ubiquitin ligases. Nat Rev Mol Cell Biol 6: 9-20.

Pfaffl, M.W., Horgan, G.W., and Dempfle, L. (2002) Relative expression software tool (REST) for group-wise comparison and statistical analysis of relative expression results in real-time PCR. Nucleic Acids Res 30: e36.

Piotrowska, M., Natorff, R., and Paszewski, A. (2000) sconC, a gene involved in the regulation of sulphur metabolism in Aspergillus nidulans, belongs to the SKP1 gene family. Mol Gen Genet 264: 276-282.

Pollmann, C., Huang, X., Mall, J., Bech-Otschir, D., Naumann, M., and Dubiel, W. (2001) The constitutive photomorphogenesis 9 signalosome directs vascular endothelial growth factor production in tumor cells. Cancer Res 61: 8416-8421.

Punt, P.J., and van den Hondel, C.A. (1992) Transformation of filamentous fungi based on hygromycin B and phleomycin resistance markers. Methods Enzymol 216: 447457.

Rao-Naik, C., delaCruz, W., Laplaza, J.M., Tan, S., Callis, J., and Fisher, A.J. (1998) The rub family of ubiquitin-like proteins. Crystal structure of Arabidopsis rub1 and expression of multiple rubs in Arabidopsis. $J$ Biol Chem 273: 34976-34982.

Sarikaya Bayram, O., Bayram, O., Valerius, O., Park, H.S., Irniger, S., Gerke, J., et al. (2010) LaeA control of velvet family regulatory proteins for light-dependent development and fungal cell-type specificity. PLoS Genet 6: e1001226.

Schwechheimer, C., and Deng, X.W. (2001) COP9 signalosome revisited: a novel mediator of protein degradation. Trends Cell Biol 11: 420-426.

Schwechheimer, C., Serino, G., Callis, J., Crosby, W.L., Lyapina, S., Deshaies, R.J., et al. (2001) Interactions of the COP9 signalosome with the E3 ubiquitin ligase SCFTIRI in mediating auxin response. Science 292: 1379-1382.

Scott, D.C., Monda, J.K., Grace, C.R., Duda, D.M., Kriwacki, R.W., Kurz, T., and Schulman, B.A. (2010) A dual E3 mechanism for Rub1 ligation to Cdc53. Mol Cell 39: 784796.

Sharon, M., Taverner, T., Ambroggio, X.I., Deshaies, R.J., and Robinson, C.V. (2006) Structural organization of the 19S proteasome lid: insights from MS of intact complexes. PLoS Biol 4: e267.

Sharon, M., Mao, H., Erba, E.B., Stephens, E., Zheng, N., and Robinson, C.V. (2009) Symmetrical modularity of the COP9 signalosome complex suggests its multifunctionality. Structure 17: 31-40.

Shevchenko, A., Wilm, M., Vorm, O., and Mann, M. (1996) Mass spectrometric sequencing of proteins silver-stained polyacrylamide gels. Anal Chem 68: 850-858.

Skaar, J.R., Florens, L., Tsutsumi, T., Arai, T., Tron, A., Swanson, S.K., et al. (2007) PARC and CUL7 form atypical cullin RING ligase complexes. Cancer Res 67: 2006-2014.

Spataro, V., Norbury, C., and Harris, A.L. (1998) The ubiquitin-proteasome pathway in cancer. $\mathrm{Br} J$ Cancer 77: 448-455.

Spielewoy, N., Flick, K., Kalashnikova, T.I., Walker, J.R., and Wittenberg, C. (2004) Regulation and recognition of SCFGrr1 targets in the glucose and amino acid signaling pathways. Mol Cell Biol 24: 8994-9005.

Suzuki, G., Yanagawa, Y., Kwok, S.F., Matsui, M., and Deng, X.W. (2002) Arabidopsis COP10 is a ubiquitin-conjugating enzyme variant that acts together with COP1 and the COP9 signalosome in repressing photomorphogenesis. Genes Dev 16: 554-559.

Szewczyk, E., Nayak, T., Oakley, C.E., Edgerton, H., Xiong, Y., Taheri-Talesh, N., et al. (2006) Fusion PCR and gene targeting in Aspergillus nidulans. Nat Protoc 1: 3111-3120.

Tan, P., Fuchs, S.Y., Chen, A., Wu, K., Gomez, C., Ronai, Z., and Pan, Z.Q. (1999) Recruitment of a ROC1-CUL1 ubiquitin ligase by Skp1 and HOS to catalyze the ubiquitination of I kappa B alpha. Mol Cell 3: 527-533.

Tateishi, K., Omata, M., Tanaka, K., and Chiba, T. (2001) The NEDD8 system is essential for cell cycle progression and morphogenetic pathway in mice. J Cell Biol 155: 571579.

Tesfaigzi, J., Smith-Harrison, W., and Carlson, D.M. (1994) A simple method for reusing western blots on PVDF membranes. Biotechniques 17: 268-269.

Tyers, M., and Jorgensen, P. (2000) Proteolysis and the cell cycle: with this RING I do thee destroy. Curr Opin Genet Dev 10: 54-64.

Vienken, K., and Fischer, R. (2006) The Zn(II)2Cys6 putative transcription factor NosA controls fruiting body formation in Aspergillus nidulans. Mol Microbiol 61: 544-554.

Wang, X., Kang, D., Feng, S., Serino, G., Schwechheimer, C., and Wei, N. (2002) CSN1 N-terminal-dependent activity is required for Arabidopsis development but not for Rub1/ Nedd8 deconjugation of cullins: a structure-function study of CSN1 subunit of COP9 signalosome. Mol Biol Cell 13: 646-655.

Wee, S., Hetfeld, B., Dubiel, W., and Wolf, D.A. (2002) Conservation of the COP9/signalosome in budding yeast. BMC Genet 3: 15.

Wei, H., Vienken, K., Weber, R., Bunting, S., Requena, N., and Fischer, R. (2004) A putative high affinity hexose transporter, $h x t A$, of Aspergillus nidulans is induced in vegetative hyphae upon starvation and in ascogenous hyphae 
during cleistothecium formation. Fungal Genet Biol 41: 148-156.

Wei, N., Chamovitz, D.A., and Deng, X.W. (1994) Arabidopsis COP9 is a component of a novel signaling complex mediating light control of development. Cell 78: 117-124.

Wu, K., Chen, A., and Pan, Z.Q. (2000) Conjugation of Nedd8 to CUL1 enhances the ability of the ROC1-CUL1 complex to promote ubiquitin polymerization. $J$ Biol Chem 275: 32317-32324.

Xirodimas, D.P., Sundqvist, A., Nakamura, A., Shen, L., Botting, C., and Hay, R.T. (2008) Ribosomal proteins are targets for the NEDD8 pathway. EMBO Rep 9: 280-286.

Yang, X., Menon, S., Lykke-Andersen, K., Tsuge, T., Di, X., Wang, X., et al. (2002) The COP9 signalosome inhibits p27(kip1) degradation and impedes G1-S phase progres- sion via deneddylation of SCF Cul1. Curr Biol 12: 667672.

Yang, X., Zhou, J., Sun, L., Wei, Z., Gao, J., Gong, W., et al. (2007) Structural basis for the function of $\mathrm{DCN}-1$ in protein Neddylation. J Biol Chem 282: 24490-24494.

\section{Supporting information}

Additional supporting information may be found in the online version of this article.

Please note: Wiley-Blackwell are not responsible for the content or functionality of any supporting materials supplied by the authors. Any queries (other than missing material) should be directed to the corresponding author for the article. 
This document is a scanned copy of a printed document. No warranty is given about the accuracy of the copy. Users should refer to the original published version of the material. 